
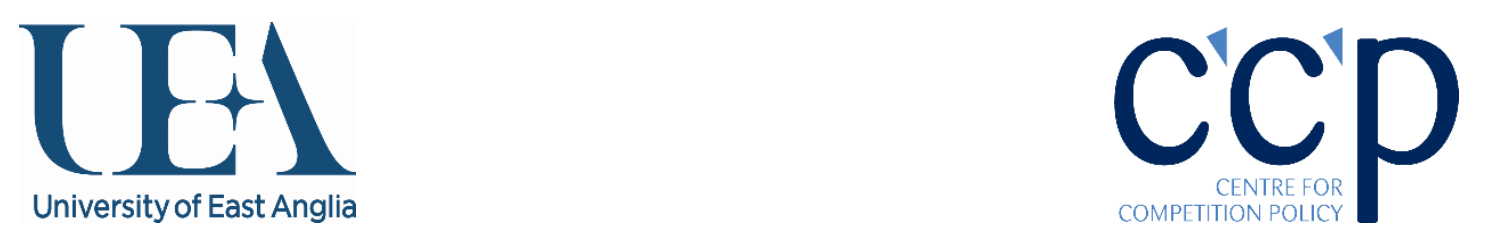

\title{
What can merger retrospectives tell us? An assessment of European mergers
}

\author{
Franco Mariuzzo \\ Centre for Competition Policy \\ School of Economics \\ University of East Anglia \\ Peter Ormosi \\ Centre for Competition Policy \\ Norwich Business School \\ University of East Anglia \\ Richard Havell \\ Charles River Associates
}

CCP Working Paper 16-4

\begin{abstract}
In this review of retrospective European merger studies we provide a discussion of the price effect of analysed mergers and examine whether the antitrust agency made the right decisions. We find that remedied mergers, on average, were not followed by a price-increase, suggesting that, in our sample, merger interventions were effective at eliminating problems. High market concentration was more likely to lead to higher post-merger prices, although remedies were able to reduce post-merger price-increases, even in concentrated markets. We look at a number of reasons why prices may increase post-merger and find little evidence of genuine agency errors.
\end{abstract}

Contact Details:

Peter Ormosi p.ormosi@uea.ac.uk 


\title{
What can merger retrospectives tell us? An assessment of European mergers*
}

\author{
Franco Mariuzzo \\ School of Economics and Centre for Competition Policy \\ University of East Anglia \\ Peter Ormosi ${ }^{\dagger}$ \\ Norwich Business School and Centre for Competition Policy \\ University of East Anglia \\ Richard Havell \\ Charles River Associates
}

13 May 2016

\footnotetext{
* This paper is partially based on a report the authors prepared for DG COMP, European Commission, titled $A$ review of merger decisions in the EU: What can we learn from ex-post evaluations?, available at: http://ec.europa.eu/competition/publications/reports_en.html). We thank Fabienne Ilzkovitz and Adriaan Dierx for their valuable input during the preparation of the report and for commenting on this paper. We are also grateful for comments on various versions of this paper to Amelia Fletcher, John Kwoka and Bruce Lyons, and the participants of the 4th E.CA Competition Law and Economics Expert Forum. The opinions expressed here are those of the authors and not necessarily those of the European Commission.

${ }^{+}$Corresponding author: Peter Ormosi, Norwich Business School, University of East Anglia, Norwich, NR4 7TJ, United Kingdom; e-mail: p.ormosi@uea.ac.uk
} 


\begin{abstract}
In this review of retrospective European merger studies we provide a discussion of the price effect of analysed mergers and examine whether the antitrust agency made the right decisions. We find that remedied mergers, on average, were not followed by a price-increase, suggesting that, in our sample, merger interventions were effective at eliminating problems. High market concentration was more likely to lead to higher post-merger prices, although remedies were able to reduce post-merger priceincreases, even in concentrated markets. We look at a number of reasons why prices may increase post-merger and find little evidence of genuine agency errors.
\end{abstract}

Keywords: mergers, merger retrospectives, ex-post evaluation

JEL Classification: K21, L40, L11 
The last two decades have seen an increasing amount of works by academics and competition authorities, trying to improve our understanding of the political economy of competition policy in the European Union (EU). Merger control has been one of the most researched areas, which is unsurprising, given that it is an ex-ante policy instrument - i.e. the antitrust agency has to assess the market effect of a transaction before the transaction takes place. In this respect even if a merger decision is based on the best available evidence, there is inevitable uncertainty in the appropriateness of any intervention that follows. Because of this, it is crucial that merger control decisions are subjected to rigorous ex-post evaluation exercises in order to assess how well they are achieving their task of filtering out anti-competitive mergers.

If done correctly, lessons learned from these ex-post studies can be channelled back into policymaking to affect how mergers are assessed in the future. As Ashenfelter, Hosken and Weinberg (2009) pointed out "Because economic models generate explicit predictions of the competitive effects of mergers, it is relatively straightforward [...] to evaluate their performance with retrospective evidence. If these tools are proven effective, they could lead to a more efficient, objective, and accurate merger review process." For example in the US hospital sector a series of retrospective merger studies revealed that some of the analytical issues had been systematically misunderstood by the courts and other policy analysts, ${ }^{3}$ and which likely have led to systematically biased judicial decisions (Ashenfelter et al. 2011). Therefore merger retrospectives contributed to an improvement of the FTC's merger enforcement programme in the hospital sector. ${ }^{4}$

Since the pioneering book by Neven, Nutall, and Seabright (1993) in the early nineties we have seen a steady increase in the number of papers that ex-post evaluate European merger decisions (merger retrospectives). ${ }^{5}$ The objective of any such work has typically been twofold: (1) to assess whether the decisions in question were right, and, (2) to understand why it might have gone wrong, with a view to improving merger analysis or decision-making going forward, either in general or in the context of that market.

A study that brings together this body of literature can be useful for numerous reasons. Firstly, this would provide a concise document that consistently summarises the corpus of relevant studies and conclude what we have learnt from European merger control. Secondly, it is an obvious way of providing evidence whether merger control works. Thirdly, it can identify areas where changes would be most pressing.

The intellectual motivator of our article is Professor John Kwoka's $(2013,2015)$ meticulously compiled study of US merger retrospectives. Kwoka collates 60 high-quality studies estimating the price effects of 53 transactions ( 46 mergers) in the US and presents the average price effects estimated by each study. For a smaller sub-sample, where he had information on the agency's merger decision, he reports price-change estimates according to the action taken by the agency as an attempt to identify if an error was made in its decision. He finds that a large proportion ex-post studies estimated that the merger led to a price increase, even when remedies were imposed upon the merger. Despite this, the strength of remedies appears to be correlated with the price effects of mergers, indicating that the authorities were capable of identifying those mergers, which posed the largest competitive concerns, and apply stronger remedies in such cases. Kwoka argues that the key problem faced by US competition authorities is the effectiveness of remedies, especially non-structural ones, rather than

\footnotetext{
${ }^{3}$ For example, the Elizinga-Hogarty market definition that had been applied in these cases generated markets that were much too large, or that not-for-profit hospitals were incorrectly assumed to not have exercised market power.

${ }^{4}$ A presentation by Daniel Hosken (FTC) at the OECD Competition Committee's Capacity building workshop on the ex-post evaluation of Competition Authorities' enforcement decisions (22 April 2015).

${ }^{5}$ In this article we use 'merger retrospectives' and 'ex-post merger evaluations' interchangeably.
} 
the identification of problematic mergers. Examination of the subset of mergers for which information on prior structural conditions is available indicates that US competition authorities are more inclined to allow increases in concentration even in cases that the Horizontal Merger Guidelines would find problematic.

Ashenfelter et al. (2009), and the OECD (2011) offer a different survey of relevant works, focusing more on methodological issues. Both works comprehensively discuss the relative advantages and disadvantages of the main methods: difference-in-differences, merger simulations, event studies, and surveys. The main conclusion is that there is no one-size-fits-all method, and specific circumstances can justify different choice of methods.

Both Kwoka and the OECD emphasise the selection problem in reviews of merger retrospectives: that academic studies are biased towards studying mergers with available data and which are on the margins of being accepted or rejected. For this reason one has to be cautious when using these studies to derive general conclusions on antitrust agencies' merger decisions. Coate (2014) attempts to control for this problem by estimating challenge probabilities for the Federal Trade Commission. These challenge probabilities were then applied to a sample of 22 studies of 19 mergers challenged by the FTC in order to infer the effectiveness of the FTC's actions. Coate finds that price-increases were estimated in cases where there was a high challenge probability, but less likely where mergers had low challenge probabilities. Because of the correlation between challenge probability and the result of the merger retrospective Coate interprets this as evidence that the current policy is efficient although the intervention may not be.

Our paper contributes to the already existing works in various ways. The first part of this paper replicates Kwoka's work and applies his method to a sample of EU mergers. We look at the estimated price impacts of these mergers and briefly assess how they vary with the type of the agency's decision. We find that on average remedied mergers were not followed by a price increase. This suggests that European merger control interventions seem effective at eliminating problems.

Exploring the relative richness of data from European merger decisions, we look at heterogeneity across the estimates, and find that more concentrated markets are more likely to lead to higher postmerger price increases. We also find that a strikingly large proportion of studies look the merger's price effect within a year from the merger, which is likely to be inadequate for picking up dynamic effects and potential market self-corrections, which typically take longer to unfold. ${ }^{6}$

Finally, we evaluate the merger decision in the light of the price-change estimates. In around half of the cases the retrospective estimate and the decision together suggest that the agency's decision was potentially erroneous. When further investigating these cases, we point out that only a small number of those are likely to represent a genuine error in the decision, and others are possibly a result of other factors (non-price effects were given priority over price effects, faulty evidence, or random error).

\section{Sample Description}

To conduct our review, we looked at all retrospective studies of mergers in the EU that were published prior to April 2016. Our sample consists of quantitative studies, which estimate the price effects of individual mergers. An important selection criterion that we adopted was to have information both on the price-effect estimates and the merger decision. Our sample size (29 mergers), where both the price-change estimate and the agency's decision is available, is similar to Kwoka's (23 mergers). Kwoka's findings are based on 23 difference-in-differences (DD) estimates, our study has 20 difference-in-differences and 9 merger simulation (MS) estimates.

\footnotetext{
${ }^{6}$ Market self-correction typically refers to the market mechanism, whereby the monopoly profit attracts entry, and thus more competition, consequently reducing prices.
} 
Throughout the discussion we do not express preference for either method as a tool for ex-post merger analysis. ${ }^{7}$ In general, because of its simplicity and overall good performance (in terms of unbiased estimates), difference-in-differences tends to be preferred over merger simulations in merger retrospectives. It is also true that, although the simulations in our sample were conducted expost, they relied on ex-ante information therefore they seemingly not fit well in our sample of merger retrospectives. On the other hand, merger simulations come with considerable shortcomings, the most notable of which is that they rest on strong - and often untestable - assumptions. Moreover, where comparisons have been made, the predictions of merger simulation are often found to differ substantially from results in difference-in-differences studies. ${ }^{8}$

Nevertheless, for expositional purposes we chose to include both methods in our analysis. Moreover, there are at least three instances where simulations shows their strengths against difference-indifferences:

1. Difference-in-differences methods always compare the observed state of the world (factual) with a counterfactual world where the merger did not happen. Because of this, it is more limited in its ability to estimate if there was an unnecessary intervention by the agency (Type I error) as it would require estimating a world with the merger, but without the intervention. This may be possible in some cases, ${ }^{9}$ but not in general. Merger simulations allow comparisons across different counterfactuals (no merger, unconditional merger, remedied merger, alternative remedy).

2. Difference-in-differences methods are unable to evaluate changes in welfare, something that can be done in merger simulations.

3. Finally, difference-in-differences may suffer of the contagious/umbrella effect, in which case the counterfactual responds to the merger, making it hard to identify the causal effect of the merger on the outcome. Merger simulations use hypothetical equilibria of the merger and the counterfactual groups (e.g. merger against the no-merger world, or a remedy against an alternative remedy world). Because of this, the counterfactual is never affected by the merger.

Our selection criteria for merger simulations was that the study was conducted after the merger, rigorous structural models were used to estimate parameters of the demand system, and these parameters were then plugged into a merger simulation to estimate the price effect of the merger. Two of the studies estimated price effects through both methods in order to compare the results and evaluate the accuracy of the simulations. We treat these as separate estimates.

\subsection{Potential Biases}

Any attempt to reach conclusions about the overall nature of merger enforcement through the analysis of a group of ex-post studies must acknowledge that the mergers analysed by individual studies are not a representative sample of all mergers. Kwoka suggests that the mergers of most interest to academics are those which raised the most antitrust questions and where the antitrust authorities faced a hard decision. He also points out that markets with publically available data will be most attractive to academics for study. This biases Kwoka's sample towards regulated industries with data reporting requirements, such as airlines and petrol retailing industries where data is often collected and released publically by third parties.

\footnotetext{
7 There is an ongoing debate in the empirical industrial economics literature on the relative merits of DiD and MS in the context of policy evaluation. Probably most prominently in: Angrist and Pischke (2010), Einav and Levin (2010) and Nevo and Whinston (2010).

${ }^{8}$ See for example: Peters (2006), Weinberg (2011), Weinberg and Hosken (2013).

${ }^{9}$ For example, in the UK mergers do not require pre-notification and thus can temporarily exist before a remedy is imposed. This temporary period can be used as a control for the merger without remedy.
} 
The sample of EU merger retrospectives collected by this study is naturally susceptible to the same biases, although given the large proportion of unconditionally approved mergers in our sample we believe it is much less likely that case selection was motivated by the complexity of the merger investigation. In any case, we acknowledge that non-random issues, such as data availability could have driven sample selection. For this reason the interpretation of our findings and conclusions should be limited to this sample and we caution against any generalisation. For example, the finding that in our sample the mean price effect is higher in unconditionally approved cases than in remedied cases must not be interpreted that in general EU antitrust agencies are prone to make mistakes when deciding which cases to intervene.

\subsection{Description of studies in the sample}

We find 22 relevant studies, examining 27 mergers. ${ }^{10}$ Two of the mergers were analysed using two different methods (DD and MS) and we assess those separately, which increases our merger sample size to 29. Table 9 in the Appendix lists all the mergers discussed in this study. All of these are true mergers (e.g. no joint ventures are included in the sample). The mergers span over 12 different industries. These industries are: hospitals with six mergers studied; supermarkets, brewing and petrol retailing with three mergers each; telecommunication and iron ore mining with two mergers each; and energy, pharmaceuticals (studied with both methods), book retailing, video game retailing, bread making and lorry trailers all with one merger each.

There is some variation in the geographical distribution of sample cases. The three main jurisdictions in the sample account for 21 of the mergers. The European Union assessed 8 of the mergers, the Netherlands 7, and the United Kingdom 6 mergers. Sweden has 3 mergers in the sample, ${ }^{11}$ France has 2 , and Spain has 1 . Two of the mergers in the sample were decided upon by competition authorities in the 1990s, the remaining mergers were in the 2000s. The earliest merger decision studied was in 1995 and the most recent in 2012. The mean lag between a merger decision and a study of that merger decision is 7 year (which explains the lack of recent mergers in the sample).

17 of the mergers were unconditionally approved, 10 were remedied, and 2 mergers in the sample were blocked by the antitrust agency. Difference-in-differences methods are used predominantly for unconditionally approved mergers, interventions (remedy or block) were more likely looked at using merger simulations. ${ }^{12}$

\section{$3 \quad$ Price effect of the transactions}

In order to summarise the effect of the analysed mergers, it is useful to reduce each study to a single figure that captures the estimated price effects. Kwoka carefully details the procedure he used to solve the same problem, which we follow. Where a single figure is reported as the measured effect, this figure is taken. When the author presents multiple figures from various specifications and indicates that a particular figure is preferred, this figure is taken. Where multiple results are presented alongside each other, then a simple mean is calculated and this is taken as the effect measured by the study. In a few cases it was necessary to convert nominal price changes into percentage figures. ${ }^{13}$

Although we make continuous references to Kwoka's work, we caution against any comparison of these figures with US studies, as the characteristics of the two samples of mergers might be very

\footnotetext{
${ }^{10}$ The sample is somewhat different from the one published in the European Commission report, 4 more mergers were added.

11 Two of these cases (GSK/AstraZeneca and Carlsberg/Pripps) were assessed by both DiD and MS.

12 This is unsurprising, as mentioned above, merger simulations enable a wider choice of counterfactuals that may be required when assessing the effect of interventions.

${ }^{13}$ One study left out for was Dobson and Piga (2013), which looked at two mergers (Easyjet/Go Fly, Ryanair/Buzz) where the price effect was expressed in absolute terms and conversion was not possible.
} 
different in the two studies. For example, it is possible (given the higher proportion of remedied mergers in the sample) that the US sample contains a higher proportion of mergers in more concentrated markets.

Table 1 displays the headline price-effect estimates, broken down by whether they detected a price increase or decrease in comparison to a counterfactual. In merger retrospectives the typical counterfactual is the merger not occurring (comparing the actual realised price with the counterfactual price). However, two of the studies relate to blocked mergers. In these cases the factual is the no-merger world against the estimated counterfactual of an unconditionally approved merger. ${ }^{14}$ Because of this, in blocked mergers an estimated price increase implies desirable outcome (as it refers to the price-increase avoided by the blocking of the merger). For this reason we judged that it would be misleading to include blocked merger estimates in this table. For the same reason we have taken out the blocked mergers from all discussion where mean price effects are reported and the blocked cases are not identifiable in the table.

We also report summary statistics for samples where we removed two 'outliers' (the two estimates for GSK/Astra Zeneca using each method, $42 \%$ and $34 \%$ ). These are displayed as (no outliers) in the tables below. ${ }^{15}$ The use of the term outlier might be somewhat deceptive in this case as these large price change estimates are exactly the ones that we should be most interested in. ${ }^{16}$ However because we are pooling average price effects together, these figures have a disproportionately large effect on the averages, which might give a misleading picture of the average price-effect. For this reason, in the narrative, we refer to the sample including these 'outliers'. Nevertheless the tables below also report a sub-sample where these cases were removed in order to highlight how they affect the reported statistics.

Table 1: Mean price effect by direction of price change and type of study

\begin{tabular}{|c|c|c|c|c|c|c|c|c|c|}
\hline & \multicolumn{3}{|c|}{ Difference-in-Differences } & \multicolumn{3}{|c|}{ Merger Simulations } & \multicolumn{3}{|c|}{ Full sample } \\
\hline & Mean (\%) & Std.dev (\%) & $\mathrm{N}$ & Mean (\%) & Std.dev (\%) & $\mathrm{N}$ & Mean (\%) & Std.dev (\%) & $\mathrm{N}$ \\
\hline Overall & 1.67 & 11.70 & 20 & 6.93 & 12.11 & 7 & 3.04 & 11.80 & 27 \\
\hline (no outliers) & -0.45 & 7.02 & 19 & 2.43 & 2.25 & 6 & 0.23 & 6.29 & 25 \\
\hline Increase & 8.8 & 13.15 & 9 & 8.19 & 12.76 & 6 & 8.55 & 12.53 & 15 \\
\hline (no outliers) & 4.65 & 4.53 & 8 & 3.05 & 1.89 & 5 & 4.03 & 3.72 & 13 \\
\hline No increase & -4.16 & 6.19 & 11 & 0 & & 1 & -3.87 & 5.99 & 12 \\
\hline (no outliers) & -1.76 & 0.59 & 11 & -0.60 & & 1 & -3.87 & 5.99 & 12 \\
\hline
\end{tabular}

The sample average price effect records an increase of three percent (no effect if outliers are excluded). A more nuanced look at the data reveals that around three-quarters of the price-change estimates are smaller than five percent. The overall mean price increase is larger when the merger simulations were used. This seems to be driven by price decreasing mergers as the average price increase seemed to be the same (8\%) irrespective of the method used. Difference-in-differences methods were more likely to report a post-merger price drop. This could be because simulations were more likely conducted on difficult to assess mergers that were more likely to lead to price increases.

\footnotetext{
${ }^{14}$ The approved merger, which in fact did not happen - is simulated.

${ }^{15}$ We identified outliers as any price-change that is more than 1.5 interquartile ranges below the first quartile or above the third quartile (in our case around a $20 \%$ price change).

${ }^{16}$ Both in the DiD and the MS samples the outlier is the GSK/Astra Zeneca merger ( $42 \%$ and $36 \%$ price increase respectively). The large price increases were probably due to the merging parties' already dominant position and the lack of entry that the agency anticipated at the time of approving the merger. The price increase in this case was likely to have been made worse by a regulation that required pharmaceutical products to be sold in smaller packages. The reduction in the size was not accompanied by a proportionate reduction in the prices, which made the large increase in the unit price a lot less conspicuous.
} 
It is important to add that, by definition, merger simulations always give a positive price change estimate if no efficiencies are incorporated in the models. Only two of the studies mentions efficiencies in detail, however, they report them by simulating the level of efficiencies that would be needed to eliminate any negative welfare effects, therefore the price-increase figure that was included in our review were all non-negative. As all these MS studies were conducted after the merger we feel that it was a forgone opportunity to not incorporate post-merger information on cost savings.

\subsection{Price effects and agency actions}

We divided the cases into three categories: approved, remedied and blocked. Kwoka distinguished between five groups of cases: cleared, opposed, ${ }^{17}$ divestiture, conduct/conditions, and no information. There are no mergers in our dataset where we do not know the agency's merger decision. Only one merger in our sample had a behavioural remedy (the weakening of vertical ties in the Scottish and Newcastle/Courage merger) so we treated all remedied mergers as a single category.

\section{Table 2: Mean price effect (\%) by intervention and type of study}

\begin{tabular}{|c|c|c|c|c|c|c|c|c|c|}
\hline & \multicolumn{3}{|c|}{ Difference-in-differences } & \multicolumn{3}{|c|}{ Merger Simulations } & \multicolumn{3}{|c|}{ Full sample } \\
\hline & Mean (\%) & Std.dev (\%) & $\mathrm{N}$ & Mean (\%) & $\begin{array}{c}\text { Std.dev } \\
(\%)\end{array}$ & $\mathrm{N}$ & Mean (\%) & $\begin{array}{c}\text { Std.dev } \\
(\%)\end{array}$ & $\mathrm{N}$ \\
\hline Approved & 3.44 & 13.35 & 14 & 13.10 & 18.10 & 3 & 5.14 & 14.15 & 17 \\
\hline (no outliers) & 0.48 & 7.73 & 13 & 2.65 & 0.07 & 2 & 0.77 & 7.19 & 15 \\
\hline Remedied & -2.47 & 5.19 & 6 & 2.31 & 2.90 & 4 & -0.55 & 4.88 & 10 \\
\hline (no outliers) & -2.47 & 5.19 & 6 & 2.31 & 2.90 & 4 & -0.55 & 4.88 & 10 \\
\hline Blocked & & & 0 & 30.65 & 35.85 & 2 & 30.65 & 35.58 & 2 \\
\hline
\end{tabular}

Table 2 shows the price outcomes of mergers by methodology and agency action. The average price increase in unconditionally approved mergers is around five percent. This seems to be driven by the merger simulation estimates and the 'outlier' study of GSK/Astra Zeneca. For remedied mergers prices, on average, did not increase $(-0.55 \%)$. Three of the 10 cases estimated positive post-remedy price change (two of them a result of merger simulation), three estimated no price change and the remaining were negative price-effect estimates.

A stylised conclusion - based solely on these findings - would be that European antitrust agencies are good at finding the right intervention, however there are some cases where intervention would have been justified (hence the average positive estimated price-effect of unconditionally approved mergers). This is in contrast with Kwoka's and Coate's main findings for US mergers, who conclude that interventions may not be efficient in US merger control.

Again, it is important to emphasise that a comparison of the effectiveness of the jurisdictions based on these findings would be misleading without knowing more of the characteristics of the cases. Firstly, limitations of small sample size apply to both samples. Secondly, it is possible that the US sample is composed predominantly of high-concentration, problematic mergers, whilst the EU sample contains more benign cases. The cases studied for ex-post evaluation are highly unlikely to represent a random sample drawn from the full set of merger decisions. For this reason the difference in the main conclusions of Kwoka's work and this study could be simply due to the differences in the way

\footnotetext{
${ }^{17}$ The prosecutorial system in the US allows for a class of mergers that we see only rarely in the EU - mergers that the agency opposed, but which were not blocked by the Court. These cases offer the potential to test for agency Type I error - i.e. if prices stay the same or go down following the merger, it would suggest a Type I error in respect of the original merger decision. In the EU, such cases rarely exists (except in very specific circumstances - e.g. where mergers are cleared only on the basis that the turnover concerned is too small or whether authorities make procedural errors which allows the merger to go through (e.g. missing deadlines). We had neither in our sample of cases.
} 
the two samples were selected. Moreover, the price effect is only one of the variables upon which the agency draws conclusions on the merger. It is equally possible that other considerations (such as quality or efficiency improvements) dominated the merger decision.

\subsection{Examining heterogeneity across merger studies}

In the absence of available data, Kwoka's study stops short of examining the heterogeneity across the analysed studies. Reporting on merger decisions tends to be more transparent in Europe than in the US, which allows us to take a cursory look at some of the merger characteristics. For example it is possible that large price-increases are typical to very concentrated markets i.e., markets that raised complex issues for investigators. It is also possible that variation in the design of the studies affected the price estimates. Finally, industry-specific conditions in some markets might be more/less susceptible to a larger/smaller price increase.

\subsubsection{Market structure}

Changes in market concentration can serve as an indicator of the likely market power effect of the merger. Accordingly, market structure considerations have a prominent place in EU merger control guidelines. Where they were available, we collected information on three different measures of market concentration (number of firms, market share of the largest merging firm, and $\mathrm{HHI}$ ), and these are introduced in Table 3.

Table 3: Market structure in the sample mergers ${ }^{18}$

\begin{tabular}{lllllll} 
& & $\mathrm{N}$ & mean & std.dev & $\min$ & $\max$ \\
\hline \hline \multirow{2}{*}{ Market shares } & & & & & & \\
\hline $\mathrm{HHI}$ & Combined post-merger & 23 & 0.35 & 0.19 & 0.07 & 0.87 \\
& Pre-merger & 15 & 2342 & 1724 & 656 & 7888 \\
& Post-merger & 15 & 2967 & 2206 & 693 & 10000 \\
Number of post mergers firms & & 23 & 7.17 & 3.43 & 1 & 15
\end{tabular}

Table 4 reports the average estimated price-effect with respect to market concentration. Our sample size was prohibitive for conducting a regression analysis therefore we are only reporting simple comparisons of means. For each measurement of market concentration we broke down the sample into two groups, below and above the median measure of concentration. For example, the median of the combined post-merger market shares is 35 percent, therefore we report the average of the pricechange estimates for cases where the combined post-merger market share is less than 35 percent and cases where it is more. In this context, a market is less concentrated if the combined market share is less than 35 percent, if the pre-merger $\mathrm{HHI}$ is less than 2050, if the post-merger $\mathrm{HHI}$ is less than 2600 , or if the number of firms in the market is more than $5 .{ }^{19}$

Table 4 suggests that market concentration is a strong driver of the estimated price-effect of the merger. Average estimates of post-merger price increase were around zero where the market was less concentrated. In more concentrated markets the average estimated price-increase was large (between $10 \%$ and $20 \%$ ). It also appears that the post-merger price increase depends on whether the agency intervened. Large price increases were observed on average if the merger had been unconditionally approved. In the sample, remedies had been able to reduce post-merger priceincreases even in concentrated markets.

\footnotetext{
${ }^{18}$ Because of missing values the frequency is lower than the total number of mergers in our sample.

${ }^{19}$ Of course this does not mean that these figures should be used as thresholds above which mergers should be intervened.
} 
Table 4: The estimated price effect of mergers by market concentration

\begin{tabular}{|c|c|c|c|c|c|c|c|}
\hline & & & Full sample & & Unconditional & & Remedied \\
\hline Measure of concentration & & $\mathrm{N}$ & $\begin{array}{l}\text { Mean price-change } \\
\text { (\%) (std.err) }\end{array}$ & $\mathrm{N}$ & $\begin{array}{l}\text { Mean price-change } \\
\text { (\%) (std.err) }\end{array}$ & $\mathrm{N}$ & $\begin{array}{c}\text { Mean price-change } \\
\text { (\%) (std.err) }\end{array}$ \\
\hline \multirow{2}{*}{$\begin{array}{l}\text { Combined post-merger } \\
\text { market share of merged } \\
\text { firms (\%) }\end{array}$} & $\leq 35 \%$ & 11 & $\begin{array}{r}0.59 \\
(2.29) \\
\end{array}$ & 9 & $\begin{array}{r}0.76 \\
(2.52)\end{array}$ & 2 & $\begin{array}{l}-0.17 \\
(0.61)\end{array}$ \\
\hline & $>35 \%$ & 12 & $\begin{array}{c}6.53 \\
(16.45) \\
\end{array}$ & 7 & $\begin{array}{c}9.67 \\
(21.50)\end{array}$ & 5 & $\begin{array}{r}2.12 \\
(3.03)\end{array}$ \\
\hline \multirow{2}{*}{ Pre-merger $\mathrm{HHI}$} & $\leq 2050$ & 7 & $\begin{array}{r}0.33 \\
(1.58) \\
\end{array}$ & 5 & $\begin{array}{l}-0.18 \\
(1.29) \\
\end{array}$ & 2 & $\begin{array}{r}1.63 \\
(1.93) \\
\end{array}$ \\
\hline & $>2050$ & 8 & $\begin{array}{c}9.71 \\
(19.00) \\
\end{array}$ & 4 & $\begin{array}{c}22.92 \\
(18.20) \\
\end{array}$ & 4 & $\begin{array}{l}-3.5 \\
(6.76) \\
\end{array}$ \\
\hline \multirow{2}{*}{ Post-merger $\mathrm{HHI}$} & $\leq 2600$ & 7 & $\begin{array}{c}0.34 \\
(2.42) \\
\end{array}$ & 4 & $\begin{array}{l}-0.22 \\
(1.49) \\
\end{array}$ & 3 & $\begin{array}{l}1.09 \\
(3.57)\end{array}$ \\
\hline & $>2600$ & 8 & $\begin{array}{c}9.71 \\
(18.92) \\
\end{array}$ & 5 & $\begin{array}{c}18.34 \\
(18.85) \\
\end{array}$ & 3 & $\begin{array}{l}-4.67 \\
(7.09)\end{array}$ \\
\hline \multirow{2}{*}{ Number of firms } & $\leq 5$ & 9 & $\begin{array}{c}7.88 \\
(18.37) \\
\end{array}$ & 7 & $\begin{array}{c}12.57 \\
(18.24) \\
\end{array}$ & 2 & $\begin{array}{c}-8.5 \\
(3.53) \\
\end{array}$ \\
\hline & $>5$ & 12 & $\begin{array}{r}1.53 \\
(2.24) \\
\end{array}$ & 5 & $\begin{array}{c}1.62 \\
(1.64) \\
\end{array}$ & 7 & $\begin{array}{r}1.46 \\
(2.72) \\
\end{array}$ \\
\hline
\end{tabular}

The sample size of course warrants a large amount of caution when trying to extrapolate from these results. Nevertheless, these figures confirm that for our limited sample of mergers, price increases happen - as theory would predict - in more concentrated markets. This would suggest that market structure may serve as a useful first screen of merger decisions. ${ }^{20}$ The price-increase in concentrated markets was eliminated in intervened mergers. This reinforces our earlier finding, EU merger control is good at finding the right intervention, however some mergers with high concentration had been unconditionally approved, and were followed by a price increase.

\subsubsection{Data window}

Studies differ considerably in their research design, which could contribute to some of the variation in the magnitude of price-effect estimates. Here we picked one particular feature, the span of the data that was used for estimating the impact of a merger or an intervention. ${ }^{21}$ We believe this is important, because it is possible that the immediate price-shock, caused by the merger, is self-corrected by the market within few years following the merger. ${ }^{22}$ It seems unlikely that the agency would choose to intervene if it believed that market correction would offset the price increase within one or two years after the merger. On the other hand, longer spanning data is more likely to contain confounding effects (effects other than the merger). For this reason, a badly chosen time period may provide misleading price-effect estimates.

Our focus is only on difference-in-differences studies, where the choice of data span is relevant. Although all the relevant studies highlighted a single price-change as a preferred estimate, some of them estimated the post-merger price impact for each consecutive year following the merger. For example the Dutch hospital merger study estimates how post-merger prices changed in the first to

\footnotetext{
${ }^{20}$ Kwoka and Gu (2015) arrive at a similar conclusions.

${ }^{21}$ Kwoka (2015, p.63) also briefly discusses the data window issue in US studies.

22 See for example Focarelli and Panetta (2003), who find that post-merger prices first increased after mergers in the bank deposit market, but from the third year following the merger they reverted to (or below) pre-merger levels.
} 
the fifth year after the merger. Although it uses the over-time average estimated price-change as its preferred one, it also reports price-change estimates for each year following the merger. For the purposes of analysing how post-merger prices evolve over time, we treat the estimates for each separately estimated years as a single observation. We recorded 48 such estimates.

Table 5 suggests a quadratic relationship between the time passed after the merger and the pricechange estimate, peaking at 2 years after the merger. Accepting the figures in Table 5 at their face value would suggest that prices only increase for a few years after the merger, and eventually drop. This however should not imply that market self-correction mechanisms fix un-remedied mergers and therefore there is no need for merger control. The un-remedied mergers were approved, exactly because the agency may have anticipated these correcting forces to eliminate any price increase. On the other hand, in remedied mergers it was probably the remedy that eliminated the price-increasing effects of the merger.

Of course these numbers have to be handled with caution, the sample size is very small for formal testing. ${ }^{23}$ Nevertheless it appears that it does matter when the study is conducted. A study using data from the immediate aftermath of the merger may not fully reflect all the effects of the merger. In choosing the appropriate time-span of the data one should take into account what the agency's decision was. For example if the agency predicted that the initial price increase would be neutralised by subsequent entry then the data should span sufficiently long to pick up these effects.

Table 5: The estimated price effects of the merger by the year of the price estimate ${ }^{24}$

\begin{tabular}{|c|c|c|c|c|c|c|c|c|c|}
\hline \multirow[b]{2}{*}{$\begin{array}{l}\text { Number of years } \\
\text { after the merger }\end{array}$} & \multicolumn{3}{|c|}{ Full sample } & \multicolumn{3}{|c|}{ Unconditionally cleared } & \multicolumn{3}{|c|}{ Remedied } \\
\hline & $\mathrm{N}$ & $\begin{array}{l}\text { Average price- } \\
\text { increase (\%) }\end{array}$ & $\begin{array}{l}\text { Std.dev. } \\
(\%)\end{array}$ & $\mathrm{N}$ & $\begin{array}{l}\text { Average price- } \\
\text { increase (\%) }\end{array}$ & $\begin{array}{l}\text { Std.dev. } \\
(\%)\end{array}$ & $\mathrm{N}$ & $\begin{array}{l}\text { Average price- } \\
\text { increase (\%) }\end{array}$ & $\begin{array}{c}\text { Std.dev. } \\
(\%)\end{array}$ \\
\hline 1 & 22 & 0.54 & 4.86 & 15 & 0.32 & 3.77 & 7 & 1.03 & 7.00 \\
\hline 2 & 11 & 6.98 & 15.56 & 10 & 7.88 & 20.36 & 1 & -2 & \\
\hline 3 & 7 & 3.11 & 7.44 & 6 & 4.63 & 6.86 & 1 & -6 & \\
\hline $4+$ & 8 & 2.06 & 4.18 & 8 & 2.06 & 4.17 & 0 & & \\
\hline
\end{tabular}

\subsubsection{The relevant industry}

In the sample there were four industries where 3 or more studies were conducted. From these, some simple observations can be made. For hospitals and brewing, the price-change estimates show considerable variation. On the other hand, for petrol retail and supermarkets the estimates are relatively small. This raises an important point. Based on price-change estimates, one would be inclined to conclude that petrol retail mergers do not harm consumers once remedies have been imposed. Any such conclusion would ignore the possibility that even a small price change can have large welfare implications in certain circumstances. Such is the case in petrol retail, as petrol prices are likely to represent a large proportion of household expenses, demand is probably very inelastic, and at retail level it is unlikely that mergers would lead to large cost savings. Without wanting to use the findings of a handful of merger price-effect estimates to make general policy conclusions, it appears that the characteristics of the analysed industry have to be taken into account when interpreting the price effect estimates. A full-fledged merger simulation would allow the analysis of the welfare impact of the merger.

\footnotetext{
${ }^{23}$ Although the price-effect measured in year 2 after the merger is significantly larger than zero.

${ }^{24}$ Because the timing of the study only varied in the case of difference-in-differences estimates (and not for simulations), this table only contains these estimates.
} 
Table 6: Price effect by industry

\begin{tabular}{lccccc}
\hline Industry & $\mathbf{N}$ & average price change & std.dev. & min & max \\
\hline Hospitals & 6 & 2.35 & 4.69 & -2.1 & 10 \\
Petrol retail & 4 & 0.67 & 0.50 & 0 & 1.2 \\
Brewing & 3 & 0.8 & 3.70 & -2 & 5 \\
Supermarkets & 3 & -0.71 & 1.46 & -2.4 & 0.26 \\
Pharmaceuticals & 2 & 38 & 5.66 & 34 & 42 \\
Iron ore mining & 2 & 3.6 & 1.41 & 2.6 & 4.6 \\
Telecommunications & 2 & 1 & 16.97 & -11 & 13 \\
Video games & 1 & -20 & & & \\
Books & 1 & 0 & & & \\
Car parking & 1 & 3 & & & \\
Energy & 1 & -6 & & &
\end{tabular}

4 Do price increases indicate a potential error by the agency?

It is important to make some clarification regarding our terminology in this section. We identify cases where the agency's decision did not eliminate a price increase. As a shorthand terminology, for the purposes of this work, we refer to these cases as 'potential errors'. We use the word potential to acknowledge that there are numerous situations where the agency made no error and yet the merger decision was followed by a price increase.

\subsection{Is a potential error really an error by the agency?}

In 15 cases in our sample the merger was followed by a price increase. It would be tempting to jump to the conclusion that the agency made an error in these decisions, however this might not necessarily be the case. Werden (2015) identifies four types of 'error' sources: faulty facts, erroneous economics, bad breaks, and random variation. He argues - and we echo this argument - that the ex-post merger study should try to investigate and establish what caused the potential error. To some extent, some of the studies in our sample did this. Where this was available, we report these findings; otherwise we try to establish the source of the potential error by combining information from the merger study and the agency's merger decision report.

Below we discuss five sources that may have led to a price increase following a merger decision by the antitrust agency. These are: (1) erroneous analysis, (2) focus on non-price effects, (3) faulty facts, (4) random variation, and (5) small price increase. We would argue that only the case of erroneous analysis can be classified as an error by the agency.

\subsubsection{Erroneous analysis}

It is possible that the agency had all information at hand that should have enabled it to reasonably predict the price increase, but it made an erroneous assessment leading up to a decision that did not stop the negative effects of the merger. One example could be the inappropriate use of quantitative techniques. An upward-price-pressure type analysis may be a good indicator of the closeness of competition in heterogeneous markets but it is sensitive to the values of input and can provide a misleading indicator for whether to conduct a detailed investigation or not. Similarly, if simulations are used in the investigation and the wrong assumption is made, then the results will suffer from the 
resulting biases. Another source of erroneous analysis might come from the inadequate analysis of available evidence, or analysis based on no solid evidence.

A good example is the merger between GSK and Astro Zeneca. According to the authors of the ex-post study a post-merger price increase was likely to be due to errors in the agency's analysis. The authors - who were involved in the investigation as experts - estimated at the time of the investigation that the merger would significantly increase prices. Yet, the agency decided to unconditionally clear the merger, based on its assessment that sufficient competition from other main market segments would prevent any such price increase, and that the coming deregulation of the pharmaceutical industry would encourage new entry and competition, which did not happen.

In the Ziekenhuis Hilversum/Gooi-Noord merger it appears that the agency expected consumers to switch, which did not happen. It is not clear from the decision and the study whether this was based on a faulty analysis or a faulty fact. Also, the ex-post study identified some other possible sources of the price increase (the merger happened shortly after market liberalisation so the pre-merger prices had been below average).

\subsubsection{Other merger impacts dominate}

In most cases the merger has a range of effects on factors other than price. For example a merger might lead to quality improvement, or wider penetration of the relevant products. In these cases even if the agency had perfectly foreseen a small price increase, these could have been tolerated if the merger positively contributed to other component of consumer welfare.

In the Agip/Esso merger prices increased for Esso. The authors of the ex post study argue that this might have been caused by the fact that Esso stations became part of a larger firm with a reputation for higher quality, so the price increase can be attributed to an upwards brand repositioning of Esso stations. Although this seems like a credible explanation (which could explain why the agency - the European Commission - allowed the merger despite the potential for a small price increase), it appears that the agency's case report only discusses market shares and concludes that the level of competition in the market should ensure that prices do not increase post-merger.

In the case of Lukoil/Jet, only Lukoil's prices increased. The ex-post study claims that this might have been due to the 'considerable expansion' in Lukoil's presence and recognition. ${ }^{25}$ However, from the case report it does not seem that agency used this as an argument for approving a potentially priceincreasing merger.

\subsubsection{Faulty evidence}

'Errors' might have been caused by relying on faulty facts, which led to inaccurate forecasts. The ex post study in these cases should investigate any potentially faulty information gathered during the investigation. One possible source of faulty information may come from surveys of industry representatives, which could have painted a misleading picture of entry conditions based on which the agency unconditionally approved the merger. If there was no entry post-merger and prices did increase, then this flawed information would have led to a potential Type II error (not intervening when it should have). Whether relying on faulty information should be recognised as an 'error' by the agency is a difficult question. From our conversations with agency officials we found that opinions differ, some seeing the use of faulty evidence as a mistake of the agency while others considering that the reliability of information used by agency may depend on the rate and quality of responses to their

\footnotetext{
${ }^{25}$ There is an interesting debate in the mergers world about whether a repositioning that is due to new ownership is necessarily a significant lessening of competition/significant impediment to effective competition (SLC/SIEC), if it would have occurred even if that new owner was not a competitor (but, for example, had different branding). In this case, one could potentially observe a post-merger price rise without this implying a SLC/SIEC or a Type II error.
} 
requests for information and therefore there are cases where verification of the evidence becomes practically impossible.

Without detailed information on the merger investigations we cannot identify which cases were based on faulty evidence. The agency would be in the best position to look at its past decisions every time a post-merger price increase is estimated, and evaluate the evidence it used for deciding on the merger.

\subsubsection{Random variation}

We need to make in important caveat that applies to all ex-post merger evaluations. In any individual merger study, a small post-merger price increase/drop may not imply an agency error. At the time of the decision post-merger prices cannot be predicted with full certainty, and randomness can overwrite even the most studious predictions, making precise price-effect predictions impossible. ${ }^{26}$

To give some illustration, say that a merger is approved without intervention and an ex post evaluation finds a price increase. Does this mean that the agency potentially made an error? During the merger investigation the agency looks at the expected price change of a merger and unconditionally approves mergers if the anticipated price change, $\Delta P \geq \widetilde{\Delta P}$, where $\widetilde{\Delta P}$ is the specific value of $\Delta P$, above which the agency intervenes a merger. In the case of an unbiased agency, $\widetilde{\Delta P}=0$.

Say that $F(\Delta P)$ is the probability distribution of $\Delta P$ : if the merger is allowed even though $E(\Delta P)>0$ then the agency makes a Type II error (allows bad mergers). If the merger is intervened even though $E(\Delta P)<0$ the agency makes a Type I error - intervenes where it should not have. If $E(\Delta P)=0$ then the agency would (rightly) allow the merger to go ahead unconditionally. But even in this case there is a $1-F(0)$ chance that the merger leads to a price increase.

To be able to decide whether the agency was right or wrong one would need to look at the distribution of $\Delta P$ that the agency observed during its investigation, and the value of $\widetilde{\Delta P}$, not just the actual $\Delta P$ that the ex-post evaluation estimated. To give a numerical example: if $\widetilde{\Delta P}$ is the median of $\Delta P$, then $1-F(\widetilde{\Delta P})=0.5$. If there are two possible price effects: -5 and +5 then $E(\Delta P)=0.5 \times(-5)+$ $0.5 \times(+5)=0$, therefore the agency is rightly deciding to allow the merger without remedy. But even a merger like this, with a zero expected price increase, will turn out, for random reasons, to raise the price about half the time. ${ }^{27}$

The above simple thought experiment suggests that there is always the possibility of a random error in the merger decision. It is needless to add that the issue of random variation is a largely abstract one in most assessments. If the ex-post study could observe the distribution of expected post-merger prices at the time of the decision then one would be able to assess whether the actual price-effect fell within the realm of random variation. Of course, we cannot think of a scenario where this would be possible and thus, unsurprisingly, we found no considerations of random variation in any of our sample studies.

In terms of how to deal with random variation at the individual case level, probably the best advice comes from Werden (2015), who argues that this 'error' is likely to only lead to small post-merger price changes. If - pre-merger - the agency had accounted for all available information, and postmerger we eliminated the possibility of all other potential errors then the remaining (random) variation in the post-merger price distribution (as anticipated pre-merger) must be small.

Of course random variation can be separated from systematic biases in merger decisions if one has a sufficiently large sample of price-effect estimates - which is the main objective of reviews such as this and that of Kwoka. For example if the mean price-effect in a large body of merger retrospectives shows an average of three percent price increase following un-intervened mergers, it would highlight a

\footnotetext{
${ }^{26}$ The importance of this point is also highlighted by Carlton (2009), and Werden (2015).

${ }^{27}$ See also Carlton (2009) for a similar argument.
} 
systematic bias of merger control being too lax. Random variation would in this case scatter the individual estimates around this mean.

\subsubsection{Small price increase}

The overwhelming majority of studies in our sample estimated a price increase of less than five percent following the merger. Some of this may be due to random variation (see above). It is also possible that a small price increase is not considered a sufficiently significant impediment to competition to justify blocking/intervening a merger.

A small price increase after the merger is likely to have a negligible effect on consumers. For this reason the agency might choose its intervention threshold as $\widetilde{\Delta P}>0$. Of course antitrust agencies will always exhibit some discretion in the selection of an appropriate threshold, particularly given the uncertainty in the market and the possibility that a merger may bring efficiency gains.

The Carlsberg/Pripps study provides evidence that the divestiture was the best possible remedy and although it raised the prices in comparison to the no-merger equilibrium, it was still preferred to blocking the merger. Although no specific explanation is given, this might be due to efficiencies that in the long run would outweigh the small price increase, or due to the expectation of new entrants who will in the long run reduce the price to the pre-merger level.

Finally, there is another issue that is important to flag up if a study finds no (or little) post-merger price-increase, especially if the market is concentrated and/or there are concerns about collusion. It is possible in these cases that the firms had been colluding before the merger and the merger was a response to changes in the dynamics of the collusive process. ${ }^{28}$ In this case the merger is less likely to further increase prices because they had already been at a collusive level. ${ }^{29}$

\subsection{Which cases are more likely to attract potential errors}

We now turn to examining the characteristics of the cases where there was a post-merger priceincrease. Based on the above discussion we define potential error as mergers that were followed by a price increase larger than one percent. For example, we could assume everything below one percent to be due to random variation, or small enough to be overridden by efficiency gains. For this reason, we changed all price changes not larger than one percent to zero and repopulated our potential error group accordingly.

Given our definition of a potential error (mergers where prices increased post-merger), the first line of Table 7 simply expresses the averages for the samples of price increasing and other mergers. Potential errors were more common in more concentrated industries (HHI differences are significant). This is no surprise. Unconditionally approved mergers make up most of our sample. The decision not to intervene in a merger in a concentrated market is more likely to turn out to be erroneous. When we removed small price changes from the potential error group we redefined this sub-sample to only include cases with larger price-effects (dominantly price-increases). Larger price-increases are connected with higher market concentration, which is very much in line with what theory would suggest. ${ }^{30}$ These findings also reinforce that measures of market concentration give a good first approximation to the likely competitive issues a merger would raise. ${ }^{31}$ Finally, price increases were more likely in merger simulation studies. As pointed out earlier, these studies always estimate a price

\footnotetext{
${ }^{28}$ Davies, Ormosi, and Graffenberger (2015) provide evidence that a breakdown in collusion is likely to lead to mergers between previous colluders.

${ }^{29}$ In the DISA/Shell study the authors point out that this could have played a role in their finding that post-merger prices did not increase.

${ }^{30}$ This was also concluded by Kwoka and Gu (2015).

${ }^{31}$ Looking at EU merger decisions, both Bergman et al. (2005), and Garrod and Lyons (2015) find that a second phase investigation was more likely in more concentrated markets.
} 
increase when efficiencies are not accounted for. Moreover, it was true that merger simulations were used for mergers that were more problematic.

\section{Table 7: Sample means broken down by potential agency error $(<1 \%$ price change assumed as zero)}

\begin{tabular}{|c|c|c|c|c|c|}
\hline \multirow{3}{*}{ Price effect ${ }^{32}$} & & \multicolumn{2}{|c|}{ no error } & \multicolumn{2}{|c|}{ potential error } \\
\hline & & $\mathrm{N}$ & mean & $\mathrm{N}$ & mean \\
\hline & & 15 & $-2.98 * * *$ & 12 & $10.55^{* * *}$ \\
\hline Number of post-merger firms & & 12 & 6.75 & 11 & 7.62 \\
\hline \multirow{2}{*}{$\mathrm{HHI}$} & Pre-merger & 9 & $1530 * * *$ & 6 & $2540 * * *$ \\
\hline & Post-merger & 9 & $1874^{* * *}$ & 6 & $3251 * * *$ \\
\hline Combined post-merger market share & & 13 & 0.33 & 10 & 0.38 \\
\hline Decision year & & 15 & 2005 & 14 & 2004 \\
\hline Method (0-DD, $1-M S)$ & & 15 & $0.13^{*}$ & 14 & $0.35^{*}$ \\
\hline Agency decision ( 0 - no intervention, 1 - intervention) & & 15 & 0.4 & 14 & 0.28 \\
\hline Number of years between merger decision and data & & 15 & 1.6 & 14 & 1.6 \\
\hline
\end{tabular}

Of course the above discussion was limited by our access to information on the individual cases. Antitrust agencies would be in the best position to investigate if there was a potential error in their decision. This may take the form of a two-step procedure, where in the first step, a quantitative expost study provides evidence of the price effect of the merger, and in the second step a qualitative investigation identifies if the predictions (for example regarding entry, or cost savings) of the agency were correct, or whether a decision error was made in anticipating some of the key effects of the merger.

\section{$5 \quad$ Why are there fewer merger retrospectives in the EU?}

Although we have seen a rise in the number of European merger retrospectives, there are still significantly more such studies carried out in the US. This of course raises the question: why is there such a gap between the two sides of the Atlantic? Of course we cannot provide a definitive answer to this question, but we can look at some of the differences between the two sets of studies that might provide at least a partial explanation.

\section{Data used}

The US studies are concentrated around a few industries: petroleum (petrol retail), academic publishing, airlines, and hospitals giving most of the retrospective studies. In Europe there is also some concentration but to a seemingly lesser extent. Also, typically industries that had more than one mergers studied were covered by the same study (e.g. the 6 Dutch hospital mergers, the 2 mining mergers, or two studies covering the 4 petrol retail mergers).

The high concentration of sampled industries in the US may be due to data availability. For example 9 studies looked at 18 mergers in the airline industry. A large proportion of these relies on the dataset published by the U.S. Department of Transportation (DOT), which is a quarterly $10 \%$ sample of all flight itineraries in the U.S. Similarly, merger retrospectives on petrol retail mergers almost invariably use data from the Oil Price Information Service (OPIS), which is high-quality, proprietary data.

\footnotetext{
${ }^{32}$ We excluded the two blocked mergers from the price effect statistics as they refer to a hypothetical price effect.
} 
Table 8: Number of mergers studied using DD in the US and in Europe (by industry)

\begin{tabular}{|c|c|c|}
\hline Number of mergers retrospectives in the US & Industry & Number of merger retrospectives in Europe \\
\hline 13 & Petroleum/petrol retail & 4 \\
\hline 10 & Academic journals & 0 \\
\hline 18 & Airlines & 0 \\
\hline 3 & Railways & 0 \\
\hline 6 & Hospitals & 6 \\
\hline 0 & Brewing & 3 \\
\hline 0 & Mining & 2 \\
\hline 2 & Microfilms & 0 \\
\hline 0 & Pharmaceuticals & 2 \\
\hline 0 & Telecommunication & 2 \\
\hline 0 & Book retail & 1 \\
\hline 0 & Video game retail & 1 \\
\hline 0 & Bread making & 1 \\
\hline 0 & Car parking & 1 \\
\hline 0 & Supermarkets & 1 \\
\hline 1 & Banking & 0 \\
\hline 1 & Breakfast syrup & 0 \\
\hline 1 & Cement & 0 \\
\hline 1 & Conventional motor oil & 0 \\
\hline 1 & Corrugating medium & 0 \\
\hline 1 & Feminine hygiene products & 0 \\
\hline
\end{tabular}

Contrary to the US, we did not find two studies in the EU sample that used data from the same source. As there are no similar EU-wide industry regulators, it is less likely that data similar to the DOT dataset is available in Europe. However, at member state level industry regulators would always be a good potential data source, which was made use of in the Dutch hospital merger studies. Of course, proprietary data would be available at EU-level, but the cost of such data might form an imperative obstacle to using them for merger studies. In places, where the agency is bound by a commitment to regularly deliver ex-post evaluations (e.g. CMA UK), it might have budgetary allocation for buying such data. On the other hand, smaller authorities are understandably more constrained by their scarce resources.

\section{Who conducted the study?}

When it comes to conducting these evaluations, agencies would be well positioned given their better access to relevant data, information about the decision, and industry sources. However, academics are more likely to be seen as representing independent opinion. Moreover, conducting a fully-fledged ex-post assessment of mergers is a resource-demanding exercise, which the authorities typically lack the time for.

In the US more than $4 / 5$ of the merger retrospectives (used in Kwoka) had officials from the FTC, DOJ, or the Government Accountability Office as authors or co-authors. In the EU, only a third of the studies were authored or co-authored by officials from competition authorities.

This difference may be explained by simple organisational anomalies between authorities on the two sides of the Atlantic. Alone in the FTC there are approximately 80 staff with PhD in applied microeconomics. ${ }^{33}$ This figure dwarfs the number of staff with similar qualifications in EU agencies. From anecdotal stories we also know that the FTC strongly supports staff research activities. Similar considerations might be less prevalent in EU agencies.

\section{Judicial review}

It is also possible that the difference in the agency's commitment to ex-post evaluations also matters. In the EU, the Court can challenge the agency's decision ex-post. This might explain why these authorities could be more reluctant to publish the results of ex-post evaluations. On the other hand,

${ }^{33}$ https://www.ftc.gov/about-ftc/bureaus-offices/bureau-economics/careers-bureau-economics. 
in the US, the Court procedure plays a much more central role in the decision-making, therefore the analysed mergers are typically not subject to further judicial review. This may explain why US authorities have more incentives (or less disincentives) to assess the decisions.

For all of the above reasons it would be important to provide more incentives to deliver ex-post merger studies in Europe. A formal commitment of the agency to such activities could help ensure that some of the budget is allocated to these activities and that political disincentives do not obstruct the decision to conduct retrospective merger analyses.

On the plus side, there are signs of more agency involvement in conducting merger retrospectives in the EU. The CMA in the UK has already been regularly conducting these studies: as it "has a public commitment to evaluate each year at least one of its previous interventions". ${ }^{34}$ Recently, the European Commission (both by commissioning external experts, and through its Chief Competition Economist's team), and the Dutch competition agency have also been active in delivering ex post assessments of their merger decisions.

\section{Conclusion}

This paper provided a detailed review of ex-post studies on the merger decisions of EU antitrust agencies. One of our objectives was to replicate Kwoka's (2013) study on US merger retrospectives with European merger cases. Although the sample size puts some obvious limitations on the general validity of our conclusions, some patterns still emerge. In the sample of European studies, mergers typically only increased prices by a small amount, and such price increases happened mainly in unconditionally approved mergers. We also found that market concentration is a strong driver of the estimated price-effect of the merger. The average price increase in markets that are considered unconcentrated based on conventional measures of concentration is around zero. In concentrated markets, on the other hand, the average price increase is large, although the remedies managed to mitigate the post-merger price hike even in concentrated markets.

The paper does not stop at summarising the individual price-effect estimates of the sample studies. We look at these estimates in combination with the merger decision to be able to identify cases where there was potentially an error in the merger decision. We tried to categorise these potentially erroneous decisions into four groups: (1) error in the analysis, (2) faulty evidence, (3) random variation, and (4) small price increase, and argue that we can only talk about a genuine error in the decision in the case of (1). The overwhelming majority of our sample studies do not seem to fall in this category. Nevertheless, the purpose of this exercise was not to identify where the agency made an error, as this could be best done by the agencies themselves on a case-by-case basis. Instead, we wanted to draw attention to the importance of authorities assessing their own decisions, identifying errors, and - if necessary - changing policies to eliminate future errors.

We strongly argue that we would need many more retrospective studies in order to be able to identify not only errors in particular decisions but errors that are more systematic in merger control. Ex-post studies of mergers are often seen as a resource intensive exercise but it needs not be the case. For example studies on mergers in the same industry may offer considerable synergies. Where data is collected on an industry, it is relatively easy to expand the time span in order to be able to assess the impact of multiple mergers.

Finally, the paper only looked at the price-effect of mergers. It would be equally important to systematically review what we know about non-price effects. Some agencies regularly conduct such evaluations, typically using qualitative tools to examine the effect of mergers on factors such as entry,

\footnotetext{
${ }^{34}$ See Shell/Rontec study, p.4.
} 
market structure, investments, or service quality. ${ }^{35}$ These studies and their review could provide an invaluable source of information, especially when paired with a price estimating ex post study.

\section{References}

Angrist, J. D. and J.-S. Pischke (2010). "The Credibility Revolution in Empirical Economics: How Better Research Design is Taking the Con out of Econometrics." The Journal of economic perspectives 24(2): 3-30.

Ashenfelter, O. C., Hosken, D., \& Weinberg, M. (2009). Generating evidence to guide merger enforcement. 5(1) Comp Policy Intl 57, 72.

Ashenfelter, O., Hosken, D., Vita, M., \& Weinberg, M. (2011). Retrospective Analysis of Hospital Mergers. International Journal of the Economics of Business, 18(1), 5-16.

Bergman, M. A., Jakobsson, M., \& Razo, C. (2005). An econometric analysis of the European Commission's merger decisions. International Journal of Industrial Organization, 23(9), 717-737.

Carlton, D. W. (2009). Why we need to measure the effect of merger policy and how to do it, National Bureau of Economic Research

Coate, M. B. (2014). "A Meta-Study of Merger Retrospectives in the United States." Available at SSRN 2333815.

Dario Focarelli and Fabio Panetta (2003) Are Mergers Beneficial to Consumers? Evidence from the Market for Bank Deposits, The American Economic Review, Vol. 93, No. 4, pp. 1152-1172.

Davies, S. W., Peter L. Ormosi, and Martin Graffenberger (2014). "Mergers after cartels: How markets react to cartel breakdown." The Journal of Law and Economics, 58(3) 519-543

Dobson, P. W., \& Piga, C. A. (2013). The Impact of Mergers on Fares Structure: Evidence from European Low-Cost Airlines. Economic Inquiry, 51(2), 1196-1217

Einav, Liran and Levin, Jonathan (2010) Empirical Industrial Organization: A Progress Report. Journal of Economic Perspectives; vol. 24, no. 2, p. 145-62.

Kwoka Jr, J. E. (2013). "Does merger control work? A retrospective on US enforcement actions and merger outcomes." Antitrust Law Journal 78.;

Kwoka, J. (2015). Mergers, Merger Control, and Remedies: A Retrospective Analysis of US Policy. MIT Press.

Kwoka, J., and Gu, C. (2015). Predicting Merger Outcomes: The Accuracy of Stock Market Event Studies, Market Structure Characteristics, and Agency Decisions. The Journal of Law and Economics, 58(3), 519-543

Lyons, B., \& Garrod, L. (2015). Early Settlement in European Merger Control. The Journal of Industrial Economics, forthcoming.

Neven, D. J., R. Nuttall and P. Seabright (1993). Merger in daylight: the economics and politics of European merger control, Centre for economic policy research London.

Nevo, Aviv and Whinston, Michael (2010) Taking the Dogma out of Econometrics: Structural Modeling and Credible Inference, Journal of Economic Perspectives. 24(2), p.69-82.

Organization for Economic Co-operation and Development, Impact Evaluation of Merger Decisions (2011), DAF/COMP(2011)24

\footnotetext{
${ }^{35}$ For example the UK Competition Commission regularly looks at a number of past mergers and interviews market players and customers
} on how market conditions developed post-merger. 
Peters, Craig, (2006), Evaluating the Performance of Merger Simulation: Evidence from the U.S. Airline Industry, Journal of Law and Economics, 49, issue 2, p. 627-49.

Weinberg, M. C., \& Hosken, D. (2013). Evidence on the accuracy of merger simulations. Review of Economics and Statistics, 95(5), 1584-1600.

Weinberg, M. C.. (2011). More Evidence on the Performance of Merger Simulations. The American Economic Review, 101(3), 51-55.,

Werden, G. J. (2015). "Inconvenient Truths and Constructive Suggestions on Merger Retrospective Studies." Journal of Antitrust Enforcement, 3(1). 


\section{Appendix}

Table 9: List of mergers included in this study (ordered by jurisdiction)

\begin{tabular}{|c|c|c|c|c|c|c|c|}
\hline Merger & Study & Jurisdiction & $\begin{array}{l}\text { Decision } \\
\text { year }\end{array}$ & Industry & $\begin{array}{l}\text { Agency } \\
\text { decision }\end{array}$ & Method* & $\begin{array}{l}\text { Price } \\
\text { effect } \\
(\%)\end{array}$ \\
\hline DISA/Shell & $\begin{array}{l}\text { Perdiguero and } \\
\text { González (2012) }\end{array}$ & ES & 2004 & Petrol retail & Approved & DiD & 0 \\
\hline Agip/Esso & Csorba, Koltay and & EU & 2007 & Petrol retail & Approved & DiD & 0.7 \\
\hline Lukoil/Jet & Farkas (2011) & EU & 2007 & Petrol retail & Approved & DiD & 0.8 \\
\hline Volvo/Scania & $\begin{array}{l}\text { Ivaldi and Verboven } \\
\qquad(2005)\end{array}$ & EU & 2000 & Car making & Blocked & MS & 5.3 \\
\hline Rio Tinto/North & Lundmark and & EU & 2000 & Iron ore mining & Approved & MS & 2.6 \\
\hline CVRD/Caemi & Wårell (2008) & EU & 2008 & Iron ore mining & Remedied & MS & 4.6 \\
\hline Carrefour/Promodes & Allain, et al. (2013) & $\mathrm{FR}$ & 2000 & Supermarkets & Remedied & DiD & -2.4 \\
\hline Vinci/GTM & $\begin{array}{c}\text { Choné and } \\
\text { Linnemer (2012) }\end{array}$ & $\mathrm{FR}$ & 2001 & Car parking & Remedied & DiD & 3 \\
\hline $\begin{array}{l}\text { Ziekenhuis Hilversum/ } \\
\text { Gooi-Noord }\end{array}$ & & NL & 2005 & Hospitals & Approved & DiD & 4 \\
\hline $\begin{array}{l}\text { Erasmus } \\
\text { MC/Havenziekenhuis } \\
\text { Rotterdam }\end{array}$ & & NL & 2005 & Hospitals & Approved & DiD & -1.3 \\
\hline $\begin{array}{l}\text { MC Alkmaar/Gemini } \\
\text { Ziekenhuis }\end{array}$ & $\begin{array}{l}\text { Kemp, Kersten, and } \\
\text { Severijnen. (2012) }\end{array}$ & NL & 2007 & Hospitals & Approved & DiD & 10 \\
\hline $\begin{array}{l}\text { St. Lucas/Delfzicht } \\
\text { ziekenhuis }\end{array}$ & & NL & 2008 & Hospitals & Approved & DiD & 4.5 \\
\hline $\begin{array}{l}\text { Walcheren/Oostersch } \\
\text { eldeziekenhuizen }\end{array}$ & & NL & 2009 & Hospitals & Approved & DiD & -1 \\
\hline $\begin{array}{l}\text { Bethesda/Scheperziek } \\
\text { enhuis }\end{array}$ & & NL & 2009 & Hospitals & Approved & DiD & -2.1 \\
\hline GSK/AstraZeneca & Björnerstedt, \& & SV & 2009 & Pharmaceuticals & Approved & DiD & 42 \\
\hline GSK/AstraZeneca & Verboven, (2013) & SV & 2009 & Pharmaceuticals & Approved & MS & 34 \\
\hline Cerealia/Schulstad & $\begin{array}{l}\text { Nilsson \& Strand } \\
\qquad(2005)\end{array}$ & SV & 2003 & Bread making & Approved & MS & 2.7 \\
\hline Carlsberg/Pripps & Friberg \& Romahn & SV & 2001 & Brewing & Remedied & DiD & -2 \\
\hline Carlsberg/Pripps & (2014) & SV & 2001 & Brewing & Remedied & MS & 5 \\
\hline Game/Gamestation & $\begin{array}{l}\text { Aguzzoni et al } \\
\text { (2013a) }\end{array}$ & UK & 2008 & Video games & Approved & DiD & -20 \\
\hline Waterstones/Ottokars & $\begin{array}{l}\text { Aguzzoni et al } \\
\text { (2013b) }\end{array}$ & UK & 2006 & Books & Approved & DiD & 0 \\
\hline Shell/Rontec & $\begin{array}{l}\text { Office of Fair } \\
\text { Trading (2014) }\end{array}$ & UK & 2012 & $\begin{array}{l}\text { Petrol and diesel } \\
\text { retail }\end{array}$ & Remedied & DiD & 1.2 \\
\hline $\begin{array}{l}\text { Scottish\&Newcastle/C } \\
\text { ourage }\end{array}$ & $\begin{array}{l}\text { Pinkse and Slade } \\
\text { (2004) }\end{array}$ & UK & 1995 & Brewing & Remedied & MS & -15.5 \\
\hline Bass/Carlsberg-Tetley & & UK & 1997 & Brewing & Blocked & MS & 56 \\
\hline Morrisons/Safeway & Skrainka (2012) & UK & 2004 & Supermarkets & Remedied & MS & 0.26 \\
\hline
\end{tabular}




\section{Studies cited and used to create sample}

Aguzzoni, L., E. Argentesi, L. Ciari, T. Duso and M. Tognoni (2013). Ex-post merger evaluation in the UK retail market for books. Discussion Papers, DIW Berlin.

Aguzzoni, L., E. Argentesi, P. Buccirossi, L. Ciari, T. Duso, M. Tognoni and C. Vitale (2013). They played the merger game: A retrospective analysis in the UK videogames market. Discussion Papers, DIW Berlin.

Allain, M.-L., C. Chambolle, S. Turolla and S. Villas-Boas (2013). The impact of retail mergers on food prices: evidence from France. mimeo.

Björnerstedt, J. and F. Verboven (2013). Does merger simulation work? Evidence from the Swedish analgesics market. Working paper, Katholieke Universiteit Leuven.

Choné, P. and L. Linnemer (2012). "A treatment effect method for merger analysis with an application to parking prices in Paris." The Journal of Industrial Economics 60(4): 631-656.

Csorba, G., G. Koltay and D. Farkas (2011). Separating the ex post effects of mergers: an analysis of structural changes on the Hungarian retail gasoline market. Discussion Papers, Hungarian Academy of Sciences.

Friberg, R and Romahn, A. (2015). Divestiture Requirements as a Tool for Competition Policy: A Case from the Swedish Beer Market, International Journal of Industrial Organization, 42:1-18.

Ivaldi, M. and F. Verboven (2005). "Quantifying the effects from horizontal mergers in European competition policy." International Journal of Industrial Organization 23(9): 669-691.

Kemp, R. G., N. Kersten and A. M. Severijnen (2012). "Price effects of Dutch hospital mergers: an expost assessment of hip surgery." De Economist 160(3): 237-255.

Lundmark, R. and L. Wårell (2008). "Horizontal mergers in the iron ore industry-An application of PCAIDS." Resources Policy 33(3): 129-141.

Nilsson, A. and N. Strand (2005). On Simulation and Reality: a Swedish example. Modelling European mergers: theory, competition policy and case studies. P. A. van Bergeijk and E. Kloosterhuis, Edward Elgar Publishing: 184-189.

Office of Fair Trading (2014). Shell - Rontec: An evaluation of the OFT's conditional clearance of the merger.

Perdiguero, J. and J. L. Jiménez González (2012). Mergers and difference-in-difference estimator: why firms do not increase prices? IREA-Working Papers, 2012, IR12/005, University of Barcelona.

Pinkse, Joris, and Margaret E. Slade (2004). "Mergers, brand competition, and the price of a pint." European Economic Review 48.3: 617-643.

Skrainka, B. S. (2012). The Geography of Grocery Demand in the UK: An Evaluation of the 2003 Morrisons-Safeway Merger. Available at SSRN 2061845, University of Chicago. 